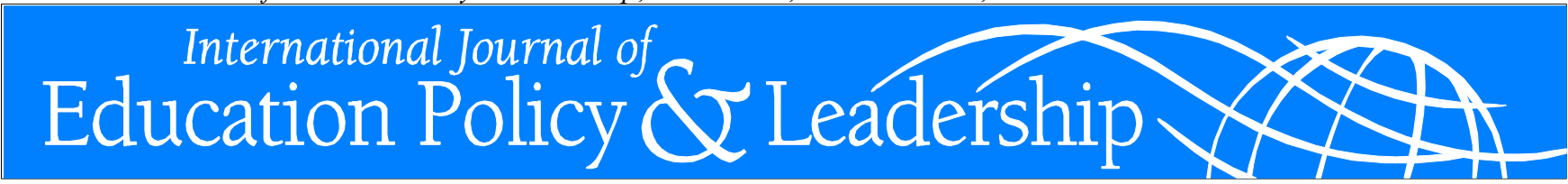

\title{
ANTECEDENTS OF TEACHERS FOSTERING EFFORT WITHIN TWO DIFFERENT MANAGEMENT REGIMES: AN ASSESSMENT-BASED ACCOUNTABILITY REGIME AND REGIME WITHOUT EXTERNAL PRESSURE ON RESULTS
}

\author{
KNUT-ANDREAS CHRISTOPHERSEN \\ University of Oslo \\ EYVIND ELSTAD \\ University of Oslo \\ ARE TURMO \\ University of Oslo
}

\begin{abstract}
This article focuses on the comparison of organizational antecedents of teachers' fostering of students' effort in two quite different accountability regimes: one management regime with an external-accountability system and one with no external accountability devices. The methodology involves cross-sectional surveys from two different management systems: (1) teachers working under assessment-based accountability $(\mathrm{N}=236)$ and $(2)$ folk-high school teachers who work without tests and examinations and, thereby, without external accountability devices $(\mathrm{N}=366)$. The purpose of the study is to estimate the path coefficients in structural equation modeling in the two regimes and compare the significance of relationships between concepts in the structural models. Through this comparison, inferences are drawn suggesting how accountability repercussions and other leadership organizational antecedents may influence teachers' fostering of students' efforts and how qualitative aspects among school professionals may influence the fostering of effort. Implications for practice and directions for future research are discussed.
\end{abstract}

Christopherson, K, Elstad, E, \& Turmo, A. (2012). Antecedents of teachers fostering effort within two different management regimes: an assessment-based accountability regime and regime without external pressure on results. International Journal of Education Policy and Leadership 7(6). Retrieved from www.ijepl.org.

\section{Introduction}

Assessment-based school accountability has considerable appeal currently, and such systems are used widely throughout the world. The strength of accountability may influence student achievement (Carnoy \& Loeb, 2002; Hanushek \& Raymond, 2005); however, other factors may also be important (de Wolf \& Janssens, 2007). One such important contributor to student learning is the teacher (Hattie, 2009).

In this article, the focus is on the link between the system of accountability and teachers' fostering of student effort. This is done by comparing the signifi- cance of organizational antecedents of fostering of effort in two different contexts of educational management: one management regime with significant external accountability and another without external accountability devices.

Why is it important to focus on teachers' fostering of student effort? "Successful learning is a function of the worthwhileness and clarity of the learning intentions, the specifications" (Hattie, 2009, p.199). Teachers need to set challenging learning intentions and tasks, and high standards for the students' effort, as effort is of vital importance for successful academic achievement. Teachers may set appropriate goals and then structure learning opportunities so that the stu-

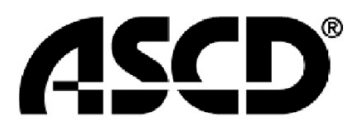

LEARN. TEACH. LEAD.
SEUSIMON FRASER UNIVERSITY THINKING OF THE WORLD

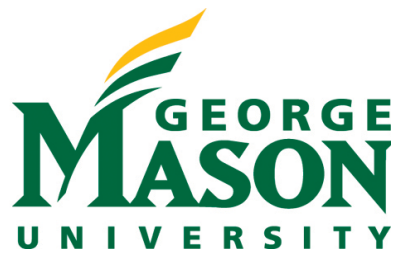


dents can reach these goals. The presence of challenging learning intentions expressed by the teacher is termed "the fostering of effort" (Hattie, 2009, p.34). This mechanism is such that "setting learning intentions invoke a 'discrepancy-creative process,' such that there is a gap between present performances and where you wish to be" (Hattie, 2009, p.199). Norwegian education authorities have emphasized that teachers should foster students' efforts, and have higher professional ambitions as a basis for teaching (White paper, 2003-04). To reinforce more fostering of effort, more external pressure put on school principals was established via assessment-based accountability. This systemic shift towards performance controlled by the use of measurements (exams, and later, national tests and school performance indicators) has been established in a few municipalities and counties.

\section{The context}

Scholars often study extreme cases because they may reveal the essential features of phenomena. In this article, two extreme examples at opposite ends of the accountability significance scale in Norway are compared. In addition, differences in the pathways showing the organizational antecedents of the fostering of effort are identified. The two different management systems in question are these: (1) teachers working under strong assessment-based accountability in a Norwegian city municipality (the capital, Oslo), and (2) Norwegian folk-high school teachers who work completely without tests and examinations, and, thereby, without any external accountability devices. Internationally compared, the system in Oslo may be characterized as accountability with moderate repercussion (Elstad, Nortvedt, \& Turmo, 2009). However, it also has to be stressed that the folk high schools in Norway do not operate without external pressure. Almost all schools have external pressures (community perceptions, public relations, and reputations at the very least).

Over the past decade, the management of the education sector in Norway and many other countries has changed significantly (Telhaug, Medias, \& Aasen, 2006). The wave of reforms known as New Public Management, along with accountability systems, has taken effect over the educational systems of several European countries (Christensen \& Lægreid, 2001). The theoretical basis for the design of external accountability systems rests on the premise that school employees need external motivation and incentives in order to work effectively (Carnoy \& Loeb, 2002).
Many countries' educational systems have seen the introduction of assessment-based accountability policies, each with different and unique features (de Wolf \& Janssens, 2007).

In comparison with other countries, the use of accountability devices in Norway is still limited. Further, in terms of applying accountability devices in education, Norway has been a latecomer (Elstad, Nortvedt \& Turmo, 2009). The mediocre results achieved in the Programme for International Student assessment (PISA) gave legitimacy to a new direction for Norwegian education policy (White Paper, 200304). A performance management system called Management by Objectives, Rules and Control has been implemented by the national government. Through a legislative change, the responsibility for educational quality has been placed on school governors. To a varying degree, complementary local accountability systems bridging the gap between school governors and schools have been set up. Local assurance systems in Norwegian education vary greatly, even though the goals are generally similar.

In the following, the core aspects of two management systems are explained: (1) management of secondary schools in the Norwegian capital of Oslo; Oslo is the municipality that has gone furthest in Norway in terms of accountability devices (Elstad, Nortvedt $\&$ Turmo, 2009); and (2) management of folk high schools where teachers work without tests and examinations, and, thereby, without external accountability devices. By comparing the organizational antecedents of the fostering of effort in these two extreme instances, conclusions about the characteristics of the two management systems are drawn.

\section{A local accountability system for schools in Oslo}

The responsibility for developing quality assurance systems in primary and secondary schools in Norway has been delegated to school governors employed at municipalities and counties, which is meant to ensure that the national regulations are upheld (White Paper, 2007-08). The education agency of the City of Oslo has established a result-oriented external accountability system that makes each school principal responsible for attaining specific statistical targets in terms of the school's activity. The education agency of the City of Oslo is responsible for primary and secondary education under the leadership of the school governors. These governors report to the local minister of education in Oslo (a politician). School principals report to 
school governors positioned in the hierarchical structure of the agency. The school governors are members of a governing body for the whole city of Oslo. Quality assurance systems have been established that make the principal responsible for results achieved and allocate to him or her an annual gradeand result-linked bonus. The intention is that the quality assurance systems increase the quality of teachers and principals. Quality teachers need to know the subject matter they are teaching and be effective pedagogues. Principals need to know how to manage schools effectively. The work of teachers in Oslo has been heavily affected by accountability devices such as tests, checks on disparities between teacher-allocated grades, and exam results (The City of Oslo Audit, 2009).

Interviews with Norwegian school principals (Elstad, 2009) created the impression that principals who pass on to the teachers the school governors' expectations of results improvements for which they themselves have been given responsibility. They use accountability tools (through average class results in tests, exams, etc.) as leadership devices: "I am able to monitor learning in the various grades in a completely new way" (Elstad, 2009, p. 180). Up to a certain point, principals attempt to absorb some of the pressure put on teachers. For instance: "I cannot put pressure on the lower levels in the hierarchy. If I do so then things get unhealthy around here" (loc. cit.).

\section{Folk high schools as a free zone}

The folk high school (FHS) is a Nordic contribution to European education and is a unique approach to non-university adult education. The FHS students vary in age, but many students are in the 18-19 age group (it is quite typical to take one year in FHS after high school). An FHS does not grant academic degrees, but the schooling emphasizes mutual teaching and conversation, and concrete formation of student participation. This endeavor has laid the ground for initiatives in favor of sustainable lifelong learning.

The core values of the FHS are in opposition to the current emphasis on tests and clearly defined teacher roles that have otherwise been prevalent in education governance in recent years. The notion of humanisticoriented self-formation of the individual (Knutas \& Solhaug, 2010) characterizes an FHS. Since there are no exams in an FHS, it is simply not possible to control learning outcomes using the result-based control carried out in other types of educational establishment without changing the whole nature of this kind of school. At a time when typical result-based management by educational authorities is a feature of most aspects of education in Norway, folk high schools still stand out as a "free zone."

External accountability devices and visions of commands via transformational leadership are at odds with the core values inherent in the FHS. The FHS originates in Grundtvig's concept of students meeting "the living word" in mutual teaching and conversation and of the concrete formation of student participation (Kulich, 2002). This experience is intended to lay a foundation for the students' lifelong, voluntary, and self-motivated learning. The moral purposes inherent in Grundtvig's concept of FHS were (1) school for life, (2) a vision of historical-poetical myths, folk culture, and cultural identity, and (3) a residential school for young adults. Thus, social life at school is seen as promoting social responsibility and civic virtues (Kulich, 2002).

In the decades that FHSs have existed, the substance of the FHS has also changed somewhat. At present, outdoor pursuits, sports, media studies, music, acting, and other topics make up the core subjects. Core values that direct the teaching processes include sustainable development, international solidarity, and reciprocal intercultural understanding. Moral mentoring is emphasized, and the "spirit" of FHSsteacher commitment and teacher obligation-is a vital aspect of the rhetoric of FHS writings. Forty-one percent of Norwegian folk high schools have a Christian identity, in which Christianity is an element in the teaching and where teachers must have a Christian faith. The degree of teacher commitment is expected to have a strong effect on teacher behavior.

Leaders of FHSs have maintained that the distinctive elements of the age period before exams and tests have become a means of product control for the processes of the educational institutions. Therefore, FHSs stand as a clear contrast to the way in which Oslo schools are run.

\section{Theoretical Model}

The fostering of effort can derive from external pressure via external accountability systems. The external pressure "can function as an important stimulus for school principals and teachers to ensure that their school 'scores as well as possible' under the threat of 'naming and shaming' in the event of sub-standard scores, and the possible effects of such public information on choices made by pupils and parents" (de Wolf \& Janssens, 2007, p. 381). The pressure on the 
principal is thus passed on internally throughout the school to the teachers. Norwegian education authorities have emphasized that teachers should foster students' efforts (i.e., apply more academic pressure in teaching, in Norwegian: "trykk i opplæringen"), and have higher professional ambitions as a basis for teaching (White Paper, 2003-04). The purpose of fostering of effort is to affect pupil decisions in a positive manner via the strategic behavior of the teachers. The teacher may guide the pupil to higher academic ambitions and higher learning intensity, and fostering of effort works through persuasion, demands, and other achievement-influencing behaviors. The central rationale behind the policy focus on teachers' fostering of effort is to raise pupil learning outcomes in core subjects.

Theoretically, the significance of accountability repercussions and other leadership organizational antecedents can influence the teachers' fostering of effort (the dependent variable). Transformational leadership (CL) and principal's relationship building (PT) are organizational antecedents in the model. Social exchange, economic exchange, and commitment represent independent variables.

The core theoretical concept is exchange. The origin of the concept of exchange lies in sociological theories of the 1950s-for instance, Merton's theory on role set (1957) and Blau's social exchange theory (Blau, 1986), which emphasizes how the distribution of power (role set) influences the structure of exchanges. This strand suggests that perceptions of social exchange may be an important determinant of employee behavior. Much human behavior is guided by considerations of exchange: "social exchange may reflect any behavior oriented to socially mediated goals" (Blau, 1986, p. 5). Shore et al. (2006) make a distinction between economic exchange (EE) and social exchange (SE). Social exchange involves a series of interactions that generate obligations to reciprocate (socio-emotional aspects of the employment relationship), while economic exchange involves more narrow perceptions of exchange. "Economic exchanges do not imply long-term or open-ended and diffuse obligations, but rather the emphasis is on economic agreements such as pay for performance" (Shore et al., 2006). The perception of exchange may or may not energize the teacher's organizational commitment (CO). Organizational commitment is "the relative strength of an individual's identification with and involvement in a particular organization" (Mowday, Steers, \& Porter, 1979, p. 226). The behavioral con- sequence of this commitment is the fostering of student effort in the teaching (LT).

Accountability devices can improve student performance through exerting greater external pressure, giving principals incentives to work more effectively and providing incentives to apply result-oriented leadership (Hanushek \& Raymond, 2005). Accountability mechanisms may, therefore, give teachers incentives to increase the fostering of student effort (which requires teachers to work harder), potentially leading to better student performance. However, this policy may also backfire (Berryhill, Linney, \& Fromewick, 2009). Examples include: through artificially inflating grades, targeting instruction to nearfailing pupils (Reback, 2008), classifying more pupils as special needs (Jacob, 2005) or as disabled (Heilig $\&$ Darling-Hammond, 2008), shifting the amount of time devoted to test subjects (Sturman, 2003), cheating by teachers on standardized tests (Jacob \& Levitt, 2003), altering the test-taking pool by strategically assigning suspensions to low-performing pupils near the test-taking period (Figlio, 2006), and so forth.

Figure 1 (next page) presents the theoretical model tested in this study, which explores what can explain the fostering of effort of (a) FHS teachers and (b) Oslo teachers. Analytical studies (Day et al., 2009; Robinson, Lloyd, \& Rowe, 2008) show interesting results on the influences of leadership. A leader's articulation of strategic declarations (transformational leadership) can influence teachers by affecting their expectations (Bass, 1985). When a principal influences the choices of a teacher via his or her perception of conditional consequences (i.e., economic exchange), then this kind of leadership works by shifting the expectations of the teachers.

Among the Oslo schools, the management system is based on assessment accountability, and as the significance of repercussions (from governing body to school) is so strong, CL plays a significant role in the internal processes of the school (i.e., in the question of how external pressure is transformed into communication and interaction between school professionals). The hypothesis is that the pathway $\mathrm{CL} \rightarrow \mathrm{SE} \rightarrow \mathrm{CO} \rightarrow \mathrm{LT}$ is important in terms of explaining the organizational antecedents of the fostering effort in Oslo schools. CL may also be persuasive and involve feelings of obligation measured as SE. In such cases, the principal plays on reciprocal feelings ("we are all in the same boat") when building relationships:

Hypothesis 1: Transformational leadership influences social exchanges within the principal-teacher 


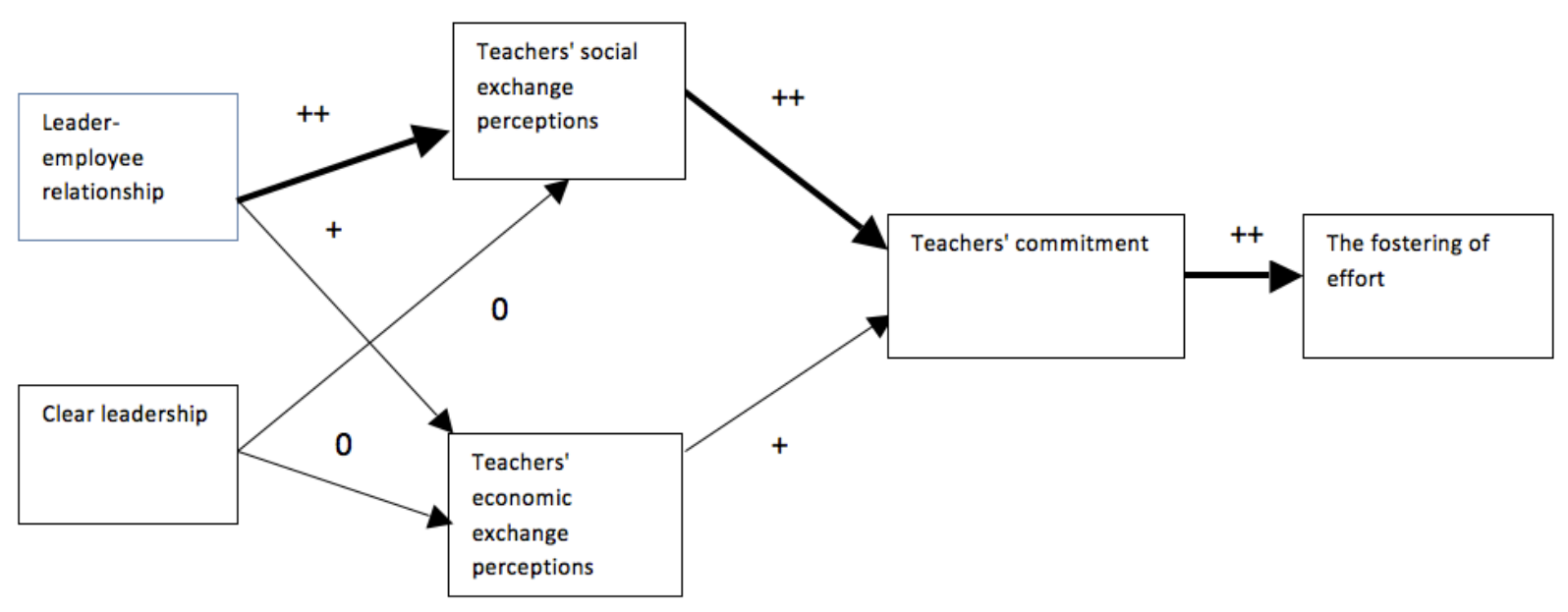

(a) Folk-high schools

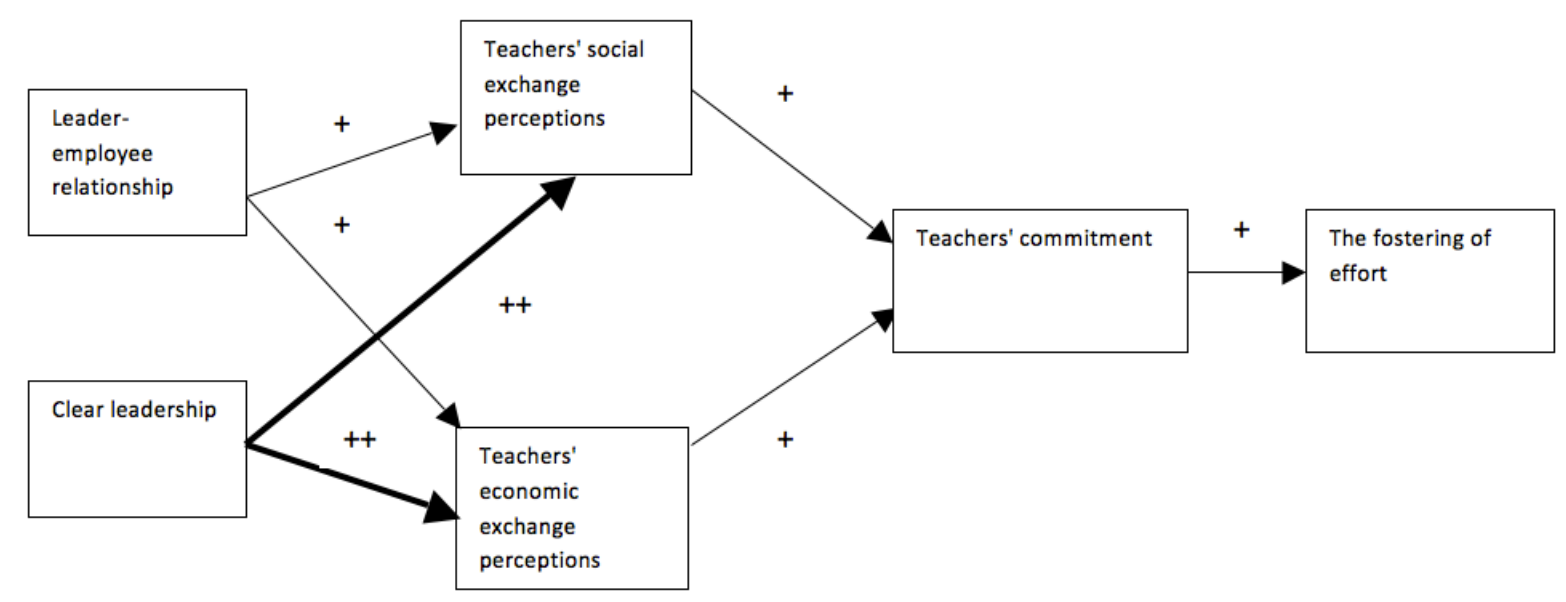

(b) Oslo schools

Figure 1. Hypothesised models of proposed relationships among variables in (a) schools working under assessment-based accountability and (b) schools who work without tests and examinations and, thereby, without external accountability devices. 0 denotes no influence, + denotes positive influence, and ++ denotes extra-positive influence.

role set, which further catalyzes teacher commitment and the fostering of effort.

The expectations in terms of $\mathrm{CL} \rightarrow \mathrm{EE} \rightarrow \mathrm{CO}$ as a pathway are more uncertain since EE does not appear to have a particular influence on work quality (Kuvaas \& Dysvik, 2009). An exploratory question is how CL, induced by external pressure, influences EE within the principal-teacher role set in a way that catalyzes fostering effort.

As far as FHSs are concerned, expectations are similar to those expressed for Oslo schools in Hypothesis 1 . CL is a relatively absent element in the FHS culture and no identifiable pathway for either $\mathrm{CL} \rightarrow \mathrm{SE} \rightarrow \mathrm{CO} \rightarrow \mathrm{LT}$ or $\mathrm{CL} \rightarrow \mathrm{EE} \rightarrow \mathrm{CO} \rightarrow \mathrm{LT}$ is posited. 
Principal, teachers, and students have distinct sets of role relationships. Trustworthiness is seen as a core feature of the social organization of schools (Coleman, 1990). Trust or lack of trust is forged when teachers discern the intentions of other teachers' actions and their leaders' actions. Trust discernments in the teacher role set are respect, competence, personal regard for others, and integrity (Bryk \& Schneider, 2002 , p. 23). Trust may take root in the teachers' beliefs regarding commitment to the purposes of schooling and may grow or unravel over time through the mutual interaction of principals and teachers.

The principal-teacher relationship is important for developing and sustaining relational trust. This "relational trust lubricates the necessary social exchanges among school professionals" (Bryk \& Schneider 2002, p. 123). An employee's perception of social exchange involves trust, mutual "investments," a long-term orientation, and obligations between the employee and the organization. With economic exchange, transactions between parties represent discrete and more short-term-oriented interactions (Shore et al., 2006, p. 839).

A principal may exert a key role in developing and sustaining relational trust among school professionals (Bryk \& Schneider, 2002, p. 137):

Hypothesis 2: Relational trust between principal and teachers (also named principal-teacher relationship) influences social exchanges within the principalteacher role set, which further catalyzes the fostering of effort among school professionals within both Oslo schools and FHS.

Social exchange theory emphasizes personal associations on the part of teachers and of students:

Hypothesis 3: Social exchange and economic exchange are distinct concepts as measured among teachers.

A significant attribute of teaching cultures under natural conditions is an obligation to carry out work of high quality with children and youths. This performance is grounded in the moral purpose behind choosing to be a teacher. This characteristic is associated with the concept of teacher commitment. Since the "spirit" of the FHS and the personal commitment of teachers are so prominent in descriptions of the FHS, the pathway teacher CO $\rightarrow$ LT appears stronger among FHS teachers than among Oslo teachers.

Hypothesis 4: Teacher commitment is an independent variable between managerial factors.

Hypothesis 5: The independent effect of commitment on learning is stronger among FHS teachers than among Oslo teachers.

\section{Methods}

\section{Sample and procedures}

Two separate electronic questionnaire surveys were carried out in 2009 and 2010. The surveys were distributed via e-mail and nonresponsive teachers were reminded at least once. The surveys include the following groups of teachers:

- All 18 schools participating in the "Leading, prioritizing and organizing: School development by focusing on learning results and teaching practices in science" project in Oslo municipality were invited to take part in a teacher survey. Eleven schools responded positively to this invitation. These schools are located in areas of differing socio-economic composition (eastern and western parts) within the Norwegian capital, Oslo. Seven are lower-secondary schools (years 8-10), three are higher secondary schools (years 11-13).

- A survey was distributed to all teachers working in Norwegian folk high schools, based on a register held by The Council of Norwegian Folk High Schools.

Table 1 shows the number of participating teachers and the response rates in the two surveys. The response rates are within the range typically found in surveys of teachers.

Table 1. The number of participants and the response rates in the three surveys.

\begin{tabular}{|l|c|c|}
\hline Survey & N & Response rate \\
\hline $\begin{array}{l}\text { Secondary } \\
\text { teachers }\end{array}$ & 236 & $54 \%$ \\
\hline $\begin{array}{l}\text { Folk high school } \\
\text { teachers }\end{array}$ & 366 & $56 \%$ \\
\hline
\end{tabular}

Table 2 (next page) shows selected background characteristics of the teachers in the two samples. The majority of the secondary teachers (Oslo) are female, while in the folk high school teachers (FHS) sample, three out of five teachers are male. Furthermore, the FHS teachers are clearly younger than the teachers in the two other samples. Only five percent of the FHS teachers are above 60 years old. Finally, the Oslo sample shows by far the largest proportion of teachers with a master's degree. Only one in four FHS teachers has a higher education with duration of two to three years. The differences between the two groups are a 
consequence of systematic selection effect in the distribution of teachers between the Oslo schools and the FHSs.

\section{Measurement instruments}

Measurement instruments previously reported in the literature (mainly by Bryk \& Schneider, 2002) are adapted and translated into the Norwegian language. In the surveys, teachers respond to items on a 7-point Likert-type scale between the categories $1=$ "Strongly disagree" and $7=$ "Strongly agree," where 4 represents a neutral mid-point.

\section{Dependent variable}

The statements offered to the teachers to measure LT include: "I set high standards for student performance," "I push the students so that they perform better," and "I make sure that the students are always confronted with challenges."

\section{Independent variables}

Six items developed by Shore et al. (2006) are used to measure SE and EE (three items each). Sample items included: "My relationship with my organization is strictly an economic one: I work and they pay me" (EE) and "I try to look out for the best interests of the organization because I can rely on my organization to take care of me" (SE). CO (Bryk \& Schneider, 2002) was used as an independent variable between the exchange concepts and the fostering of effort. One sample item for CO is: "I feel loyalty to this school."

Bryk and Schneider's (2002) principal-teacher relationship (PT) construct is used. Sample items are: "In this school it is OK to discuss feelings, concerns, and frustrations with the school's leadership" and "The principal expresses a personal interest in teacher professional development." Bass (1985) used the term "transformational leadership," which reflects a principal's influence on teachers. A new political rhetoric of transformational leadership uses the terms "powerful" or "clear" leadership. In the Norwegian debate, powerful leadership (CL) means that principals put more direct pressure on teachers. Three items related to transformation leadership are adapted to a school context. One sample for CL is: "Communication with the management helps me to understand what is expected of me in order that the school can achieve its goals."

\section{Analysis}

Theoretical considerations are the point of departure for the item selection and repeated confirmatory factor analysis (CFA) is used to identify the best indicators for the different constructs. The assessments are based on the $\mathrm{p}$ value for the $\mathrm{X}$ 2-statistic, root mean square error of approximation (RMSEA), goodness-offit index (GFI), and comparative fit index (CFI). The standard criteria $\mathrm{p}>.05$, GFI and $\mathrm{CFI}>.95$, and RMSEA $<.05$ are used for good fit and the criteria $\mathrm{p}>$ .05 , GFI and CFI $>.90$, and RMSEA $<.08$, for acceptable fit between the model and the data (Kline 2005; Blunch, 2008). Items that do not meet these criteria are omitted. Three items for each construct are used to put the latent variable into effect. In addition, Cronbach's alpha is above .70 for all these scales based on three items each. The internal consistency is considered acceptable. The CFA analysis is conducted using AMOS 18 and SPSS a8 for Cronbach's alpha.

The structural model is assessed in the same way as the measurement model using AMOS 18. According the values RMSEA $=.042, \mathrm{p}<.000, \mathrm{GFI}=.965$, and $\mathrm{CFI}=.977$, the structure model provides an acceptable fit to the data.

Table 2. Background characteristics of the teachers in the three samples (\%).

\begin{tabular}{|l|c|c|}
\hline & $\begin{array}{c}\text { Oslo } \\
N=236\end{array}$ & $\begin{array}{c}\text { FHS } \\
N=366\end{array}$ \\
\hline Gender & & \\
\hline Female & 64 & 41 \\
\hline Male & 36 & 59 \\
\hline Age & & \\
\hline$<25$ years & 0 & 2 \\
\hline $25-29$ years & 14 & 15 \\
\hline $30-39$ years & 31 & 31 \\
\hline $40-49$ years & 15 & 27 \\
\hline $50-59$ years & 27 & 21 \\
\hline$>60$ years & 14 & 5 \\
\hline Level of education & & \\
\hline $2-3$ years higher education & 3 & 27 \\
\hline $\begin{array}{l}4-5 \text { years higher education, bache- } \\
\text { lor level }\end{array}$ & 60 & 48 \\
\hline Master's degree & 31 & 14 \\
\hline Other/not specified & 6 & 11 \\
\hline
\end{tabular}

\section{Results}

The results from the structure model are summarized as follows (see Figures 2, next page, and 3, pg. 9). All the fit indices (RMSEA, CFI, and GFI) indicate acceptable fit. The chi-square statistics do not quite support this conclusion; however, chi-square statistics 
are heavily influenced by sample size and should count less in the conclusion than the other fit indices.

In both instances, it was pathway $\mathrm{PT} \rightarrow \mathrm{SE} \rightarrow \mathrm{CO} \rightarrow \mathrm{LT}$ that was the most significant in explaining organizational antecedents of the fostering of student effort. This is not surprising for the FHS, but is somewhat surprising in the case of the Oslo schools. A possible interpretation is that the quality of relationships between the principal and the teachers is the most significant prerequisite quality-ensuring processes in typical "schools." If this is the case, it indicates a limitation of New Public Management techniques, or at least a complementary quality for human relationships, which a management system should take into account. Furthermore, the results show that the relationship between teacher commitment and fostering of effort is strongest in the Oslo sample (.71) (followed by FHS at .38). This is surprising because "spirit" and moral calling are more prominent attributes in descriptions of FHS than of
Oslo schools. The results further indicate that transformational leadership has positive effects on both social exchange (.33) and economic exchange (.19) in the Oslo sample, while no corresponding positive effects are established in the FHS sample. The latter is not surprising, because transformational leadership has no clear tradition within the FHS. There are also no external management systems to back up the communication of goals for statistical targets within the institution. Other than simple completion of the course, there are no result-based statistics within the FHS. The influence of the leadership occurs principally through relationship building.

It is also not surprising that $\mathrm{CL} \rightarrow \mathrm{SE} \rightarrow \mathrm{CO} \rightarrow \mathrm{LT}$ is a fairly prominent pathway in the Oslo school. In contrast, $\mathrm{CL} \rightarrow \mathrm{EE} \rightarrow \mathrm{CO} \rightarrow \mathrm{LT}$ is a much weaker pathway. Furthermore, in both samples, strong positive relations between transformational leadership and positive principal-teacher relationships, and between principal-teacher relationships and social exchange,

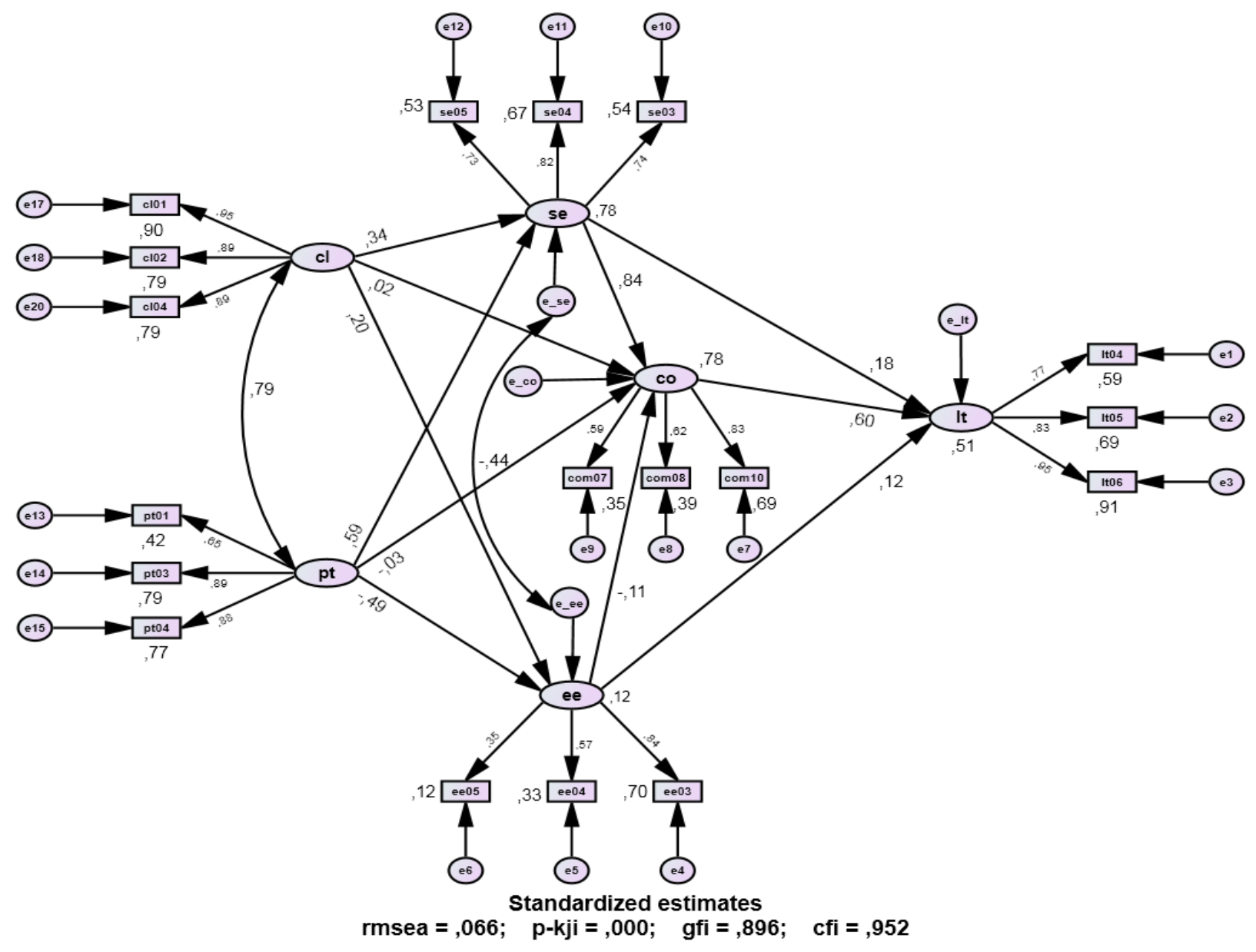

Figure 2. School teachers in Oslo $(n=236)$ 


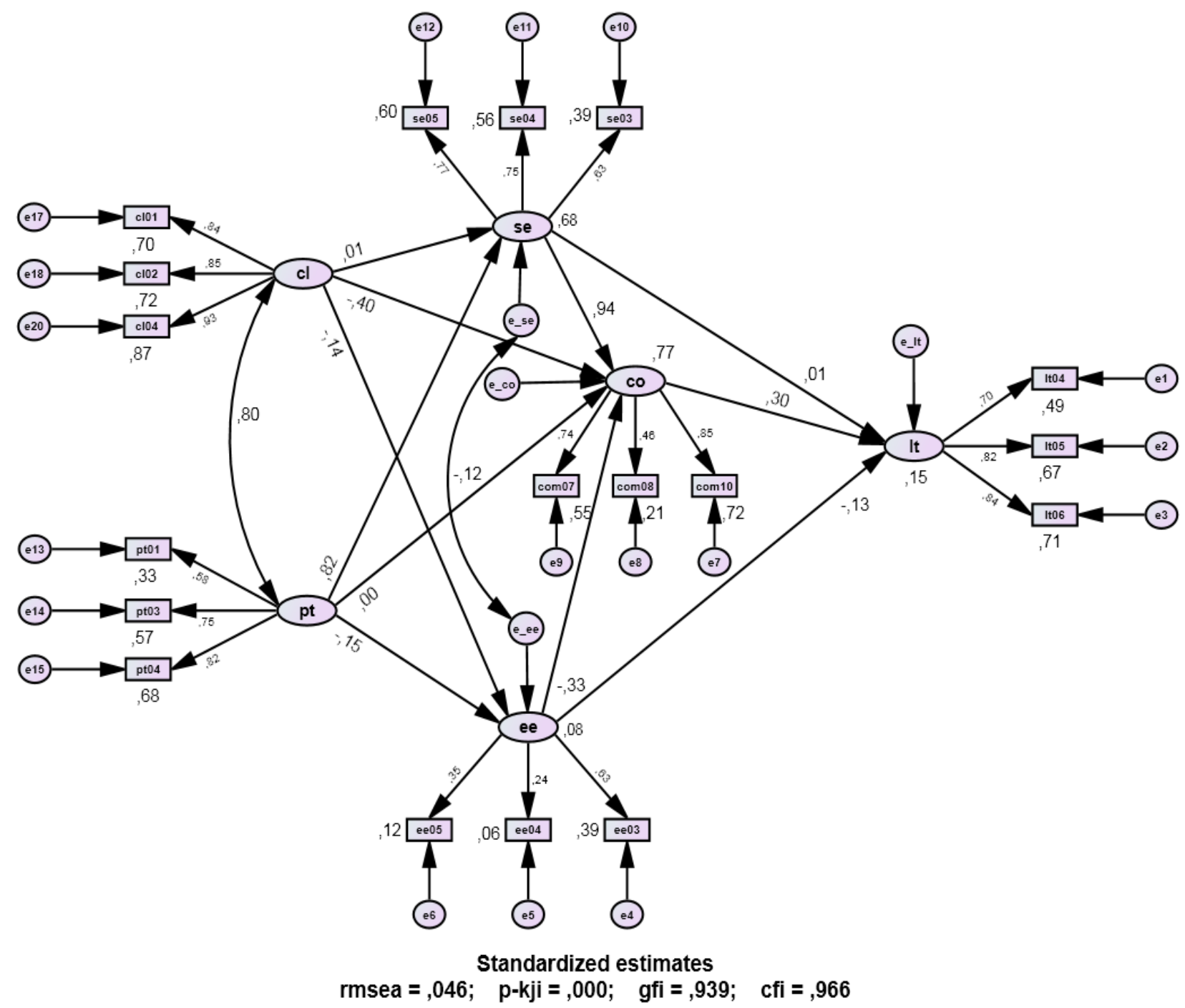

Figure 3. Folk high school teachers

are established. In both samples, principal-teacher relationships are negatively related to economic exchange: the poorer the relationship, the higher the teacher emphasis on economic exchange. Finally, in all samples, economic exchange is negatively related to commitment. This is seen most strongly in the FHS sample (see Tables 3 and 4, next page).

\section{Discussion}

The management systems for Oslo schools and for FHSs represent the extreme ends of a scale in Norway running from rather high accountability significance to almost no accountability significance. The purpose of the present study is to explore the link between the significance of accountability and teachers' fostering of student effort, among teachers working under assessment-based accountability and school professionals who work without tests and examinations (and, therefore, without accountability devices). The present study develops structural equation models to examine the factors that affect the fostering of effort within the two management systems. Structural equation modeling has been seen as a useful technique for specifying, estimating, and testing hypothesized models describing asserted causal relations among variables (Kline, 2005); thus, it is used in the current study to explore leadership organizational antecedents and the nature of exchanges between parties in the organization of teachers' work and to examine the relative effect of these aspects on the teachers' fostering of student effort. By focusing on organizational antecedents to exchange perceptions, the current study explores factors that lead to the fostering of ef- 
Table 3. Estimated Effect Components for the Structural Model with Fostering of Effort as Dependent Variable, Oslo sample $(N=236)$

\begin{tabular}{lccccc}
\hline & Correlation & Total & $\begin{array}{c}\text { Direct } \\
\text { effect }\end{array}$ & $\begin{array}{c}\text { Indirect } \\
\text { effect }\end{array}$ & $\begin{array}{c}\text { Spurious } \\
\text { effect }\end{array}$ \\
\hline Transformational leadership & .54 & .25 & .00 & .25 & .00 \\
Soft leadership & .56 & .36 & .00 & .36 & .00 \\
Social exchange & .65 & .68 & .17 & .50 & -.03 \\
Economic exchange & -.25 & .06 & .10 & -.06 & -.31 \\
Commitment & .70 & .60 & .73 & .00 & .10 \\
\hline
\end{tabular}

$\mathrm{R}^{2}($ Learning $)=.15$

fort. Path coefficients measure the degree of effect induced by one variable in the arrow-pointed variable.

The analysis undeniably provides some surprises given the underlying theoretical assumptions. The largest surprise is that statistical associations between teacher commitment and the fostering of effort are clearly stronger among Oslo teachers than among FHS teachers. This contradicts expectations, and this empirical finding should be followed up for validation in further research. In addition, further research could contribute to a better understanding of the explanatory mechanisms regarding this phenomenon.
We have evidence to indicate that $\mathrm{CL} \rightarrow \mathrm{SE} \rightarrow \mathrm{CO} \rightarrow \mathrm{LT}$ is, as expected, a significant positive chain of mechanisms among the Oslo schools but this pathway is nevertheless not as significant as the pathway $\mathrm{PT} \rightarrow \mathrm{SE} \rightarrow \mathrm{CO} \rightarrow \mathrm{LT}$. This is also somewhat surprising, even though other research supports the significance of relational trust among school professionals (Bryk \& Schneider, 2002; Tschannen-Moran, 2003). This can mean that relational trust is a strong potential inherent quality attribute in schools despite the presence of new management forms based on assessment-based accountability.

Table 4. Estimated Effect Components for the Structural Model with Fostering of Effort as Dependent Variable, FHS sample $(N=366)$

\begin{tabular}{lccccc}
\hline & Correlation & Total & $\begin{array}{c}\text { Direct } \\
\text { effect }\end{array}$ & $\begin{array}{c}\text { Indirect } \\
\text { effect }\end{array}$ & $\begin{array}{c}\text { Spurious } \\
\text { effect }\end{array}$ \\
\hline Transformational leadership & .13 & -.09 & .00 & -.09 & .00 \\
Soft leadership & .21 & .27 & .00 & .27 & .00 \\
Social exchange & .28 & .29 & .01 & .28 & -.01 \\
Economic exchange & -.29 & -.24 & -.13 & -.11 & -.05 \\
Commitment & .37 & .30 & .30 & .00 & .07 \\
\hline
\end{tabular}

$\mathrm{R}^{2}$ (Learning) $=.51$ 
It is not surprising that $\mathrm{CL} \rightarrow \mathrm{SE} \rightarrow \mathrm{CO} \rightarrow \mathrm{LT}$ is the least active in FHS. The coupling to $\mathrm{CL}$ is altogether an artificial question when considering the world of the FHS. To what extent the FHS has anything to gain from considering management systems that include goal management and result-based controls is a question that cannot be answered on a research basis because a question of this sort involves a choice of values. However, it can be seen here that the ideas of New Public Management are on a collision course with the core ideas of the world of the FHS.

As previously mentioned, the theoretical basis for the design of external accountability systems rests on the premise that school employees need external motivation in order to work effectively (Carnoy $\&$ Loeb, 2002). On this basis, some people regard these systems as an expression of mistrust of teachers as professionals (Ingersoll, 2003), and accountability and professionalism are seen as conflicting perspectives (Tschannen-Moran, 2009). It is essentially difficult to couple incentives to the work of the teacher, because the results of the teacher's work are not directly visible, nor can they be measured in a direct sense. In human resource management theory, emphasis is placed on the "warm-blooded" aspects of the view of how the systems should be designed (Pfeffer \& Veiga, 1999)_for instance, to motivate teachers towards good performance. In this theoretical approach, social norms are of relevant significance. The theory of social norms (Coleman, 1990) can also be connected to the idea that skills in the professional functions of teaching should be vocationally related.

The professional model favors the ideal of the traditional professional-operating method, the core idea of which is the autonomy of the professional (Johnson, 1972; Tschannen-Moran, 2009). A career can be termed a profession when collegial control is exercised over it, and when social norms regulate its operation in accordance with specific professional ideals. The concept of the professional is not inconsistent with management from above, but tensions can arise between the two models if the management is exercised inappropriately (O'Day, 2002). Some researchers argue that external accountability systems may involve too much control, too much bureaucracy, and too much management from above (Ingersoll, 2003). Motivational research shows that certain forms of extrinsic motivation can remove intrinsic motivation (Deci, 1975).

As with all similar studies, this study has certain limitations from a methodological, as well as a conceptual, perspective. Nevertheless, these limitations contribute to a clear foundation for future studies. First, the cross-sectional nature of the current study means that it only represents two instant images of two organizations and does not allow us to test causal relationships among organizational antecedents of the fostering of effort and inducement of exchanges between employer and employees. More experimental and longitudinal research is needed to address the complexity of interaction dynamics between principals and teachers and the associated inducements on teachers' motivation to put pressure on students' learning processes. Quasi-experimental approaches also offer themselves as an interesting strategy when experiments in natural settings are difficult to accomplish. More research along the same lines can help promote understanding of the assumed causal relationships.

A second shortcoming is the use of self-reported questionnaire data. The subjective component of such data is undeniable. Nevertheless, independent judgments can provide interesting data about an employee's performance.

A third shortcoming is that this article looks only at factors that can affect students related to the teacher. This might be seen as a limitation since other potential variables are excluded. Further, in the current study, the teachers' self-reporting is not coupled with objective goals in terms of their task performance because it was not possible to examine the associations between the fostering effort and student learning outcome. This would have been extremely difficult in this instance because FHS and the Oslo schools have a student base that does not allow direct comparisons in terms of ages.

Only a limited number of organizational antecedents of teachers' fostering of effort have been examined. One challenge in measuring such factors is that measurement becomes increasingly difficult in proportion to the remoteness of the factor in the hierarchical organization of the education sector. An improvement possibility is to examine some cases in depth in order to attain a better understanding of organizational antecedents of the fostering of effort through teaching. It would thus be possible to research the phenomena in greater depth.

The relation between external pressure $\rightarrow$ attitudes $\rightarrow$ behavior may not be linear (Creemers $\&$ Kyriakides, 2008). The functioning of external pressure via accountability systems may be lower than an optimal value of pressure. If this is the case, one would see a positive linear relation between pressure and performance. If, on the other hand, the pressure is 
higher than the optimal value, one could identify a negative relation between pressure and performance.

A final limitation is that the response rate leaves uncertainty about whether the selection is representative. However, a rate in this range is not unusual in social science studies.

\section{Policy and leadership implications}

Despite its limitations, this study contributes to our understanding of how the significance of accountability repercussions via transformational leadership and leadership organizational antecedents (relationship building) can influence fostering efforts. If the associations between the independent, the independent variables, and the dependent variable represent causal relationships, our findings may have implications for education policymaking and leadership.

This investigation contributes to the established scholarly discussion on the balance between human resource management, which emphasizes relational trust among school professionals (Bryk \& Schneider, 2002), and external accountability pressure via transformational leadership, which is important in policymaking (Carnoy \& Loeb, 2002). In an era of school accountability, it is important to emphasize that the quality of relationships among school professionals makes a difference in accountability pressure the more the fostering of effort unfolds. A significant category of quality-enhancing mechanisms in both surveys is the pathway of principal-teacher relation $\rightarrow$ social exchange $\rightarrow$ the fostering of effort. Uncertainty is the teacher's lot in life, and good relationships can contribute to reducing teacher uncertainty and vulnerability (Lortie, 1975), which in turn can be a catalyst for a greater fostering of effort. When relationships with the principal are good, external accountability pressure may be easier to live with (as indicated in the Oslo survey). It is also conceivable that principal-teacher trust underpins social norms, which create conditions for sustaining the fostering of effort among teachers (as indicated in both surveys).

The policymaking challenges of the FHS sector are difficult cases. Just like all other sectors, the FHS has its issues in terms of quality control. Whether introducing New Public Management to this sector would be an answer to these issues is a matter about which we would not wish to express an opinion. However, these results give an indication of how the nature of social practice among school professionals can create conditions for how education policies can be operated. Principal-teacher trust is an astonishingly strong factor; however, the analysis of the Oslo material indicates that goal-based management through transformational leadership can indirectly influence the performance of school staff through the exercise of the fostering of effort. With due respect for the complexity of leadership and policy making issues, it is clearly difficult to propound concrete universal principles of leadership and policy implementation.

The material from Oslo reveals statistical associations between transformational leadership and the fostering of effort (as well as indirect ones via social exchange); however, these are of moderate extent, while leadership does not seem to act through economic exchange. This is not an argument against accountability regimes, though the results can be interpreted as suggesting that accountability pressure via transformational leadership as policy making should preferably be combined with appropriate human resource management (i.e., the organizational function that deals with issues related to human development such as employee motivation and training).

During the past decade in Norway-as in many other countries-accountability devices have been established in systems of education governance (except FHS). These devices put pressures on schools imposed by external accountability systems. When the next level above the school makes demands, the principal can be caught in an intractable dilemma. If the statistical associations reflect causal mechanisms, the current study can be seen as an argument suggesting that the principal-teacher's relationship building (perhaps in combination with transformational leadership) is more useful in persuading teachers to give more than either a purely confrontational line or an approach involving financial incentives are. The challenges of a school are often so complex that the scope for meaningful bureaucratic control and incentive management is not great (O'Day, 2002). The significance of relational trust appears as a complementary factor to those which are the popular chorus of today: accountability repercussions, target management, and control. Inherent in this is an acknowledgement that tough management systems in the educational sector can have limitations in spite of attempts to extend the areas of control and measurement of the schools' processes and product. Increasing the knowledge base in relation to how school management decisions can influence the nature of the exchange relationship through teachers' attitudes and behaviors has a high relevance for practice and for policy shaping, and for how teachers perceive organizational conditions and education policies. 


\section{References}

Bass, B. M. (1985). Leadership and performance. New York, NY: Free Press.

Berryhill, J., Linney, J.A., \& Fromewick, J. (2009). The effects of educational accountability on teachers: Are policies too stress provoking for their own good? International Journal of Education Policy and Leadership, 4(5), 1-13.

Blau, P. (1986). Exchange and power in social life. New York: John Wiley and Sons.

Blunch, N. J. (2008). Introduction to structural equation modeling using SPSS and AMOS. London: Sage Publications.

Bryk, A. S., \& Schneider, B. (2002). Trust in schools. A core resource for improvement. New York: Russell Sage Foundation.

Carnoy, M., \& Loeb, S. (2002). Does external accountability affect student outcomes? A CrossState Analysis. Educational Evaluation and Policy Analysis, 24(4), 305-331.

Christensen, T. \& Lægreid, P. (2001). New public management. The transformation of ideas and practice. Aldershot: Ashgate.

Coleman, J. S. (1990). Foundations of social theory. Cambridge: Harvard University Press.

Creemers, B. P. M., \& Kyriakides, L. (2008). The dynamics of educational effectiveness: A contribution to policy, practice and theory in contemporary schools. Abingdon, England: Routledge.

Day, C., Sammons, P., Hopkins, D. Harris, A., Leithwood, K., Gu, Q., Brown, E. Ahtaridou, E. \& Kington, A. (2009). The impact of school leadership on pupil outcomes. Research Report DCSFRR108, Final Report. Retrieved December 4, 2009, from:

http://www.dcsf.gov.uk/research/data/uploadfiles/ DCSF-RB108.pdf

Deci, E. (1975). Intrinsic motivation. New York: Plenum Publishing Corporation.

de Wolf, I. F., \& Janssens, F. J. G. (2007). Effects and side effects of inspections and accountability in education: an overview of empirical studies. Oxford Review of Education, 33(3), 379-396.

Elstad, E. (2009). Schools which are named, shamed and blamed by the media: school accountability in Norway. Educational Assessment, Evaluation and Accountability. 21, 173-189.

Elstad, E., Nordtvedt, G. A., \& Turmo, A. (2009). The Norwegian assessment system: An accountability perspective. CADMO, 17(2), 89-103.
Figlio, D.N. (2006). Testing, crime and punishment. Journal of Public Economics, 90(4-5), 837-851.

Hanushek, E. A., \& Raymond, M. E. (2005). Does school accountability lead to improved performance? Journal of Policy Analysis and Management, 24(2), 297-327.

Hattie, J. (2009). Visible learning. A synthesis of over 800 meta-analyses relating to achievement. London: Routledge.

Heilig, J. V., \& Darling-Hammond, L. (2008). Accountability Texas-style: The progress and learning of urban minority students in a high-stakes testing context. Educational Evaluation and Policy Analysis, 30(2), 75-110.

Ingersoll, R.M. (2003). Who controls teachers' work? Power and accountability in America's schools. Cambridge, MA: Harvard University Press.

Jacob, B.A. (2005). Accountability, incentives and behavior: Evidence from school reform in Chicago. Journal of Public Economics, 89(5-6), 761796.

Jacob, B., \& Levitt, S. (2003). Rotten apples: An investigation of the prevalence and predictors of teacher cheating. Quarterly Journal of Economics, 153(3), 843-878.

Johnson, T. (1972). Professions and power. London: MacMillan.

Kline, R. B. (2005). Principle and practice of structural equation modeling. New York: The Guildford Press.

Knutas, A., \& Solhaug, T. (2010). "As a song in the mind." The students' learning dividends from folk high schools (in Norwegian). Retrieved October 4, 2010, from:

http://www.regjeringen.no/upload/KD/Vedlegg/Ra pporter/Elevers_utbytte_folkehoegskolen.pdf

Kulich, J. (2002). Grundtvig's educational ideas in Central and Eastern Europe and the Baltic states. Copenhagen: Forlaget Vartov.

Kuvaas, B., \& Dysvik, A. (2009). Perceived investment in permanent employee development and social and economic exchange perceptions among temporary employees. Journal of Applied Social Psychology, 39(10), 2499-2524.

Lortie, D. (1975). School teacher. Chicago, IL: University of Chicago Press.

Merton, R. (1957). Social theory and social structure, revised edition. Glencoe, IL: Free Press.

Mowday, R. T., Steers, R. M., \& Porter, L. W. (1979). The measurement of organizational commitment. Journal of Vocational Behavior. 14, 224-247. 
O'Day, J. (2002). Complexity, accountability, and school improvement. Harvard Educational Review, 72(3), 293-330.

Pfeffer, J. \& Veiga, J. F. (1999). Putting people first for organizational success. Academy of Management Executive, 13, 37-48.

Reback, R. (2008). Teaching to the rating: School accountability and the distribution of student achievement. Journal of Public Economics, 92(56) 1394-1415.

Robinson, V. M. J., Lloyd, C. A., \& Rowe, K. J. (2008). The impact of leadership on student outcomes: An analysis of the differential effects of leadership types. Educational Administration Quarterly, 44(5), 635-674.

Shore, L. M., Tetrick, L. E., Lynch, P., \& Barksdale, K. (2006). Social and economic exchange: Construct development and validation. Journal of Applied Social Psychology, 36(4), 837-867.

Sturman, L. (2003). Teaching to the test: Science or intuition? Educational Research, 45(3), 261-273.

Tschannen-Moran, M. (2003). Fostering organizational citizenship: Transformational leadership and trust. In W.K. Hoy \& C.G. Miskel, Studies in leading and organizing schools (pp. 157-179). Information Age Publishing: Greenwich: CT.
Tschannen-Moran, M. (2009). Fostering teacher professionalism: The role of professional orientation and trust. Educational Administration Quarterly, 45, 217-247.

Telhaug, A. O., Mediås, O. A., \& Aasen, P. (2006). The Nordic model in education: Education as part of political system in the last 50 years. Scandinavian Journal of Educational Research, 50(3), 245283.

The City of Oslo Audit. (2009). Grades in primary and lower secondary schools-Are the students treated equally? (in Norwegian). Report 9/2009. Retrieved 4 December 2009 from:

http://www.kommunerevisjonen.oslo.kommune.n o/getfile.php/kommunerevisjonen $\% 20 \% 28 \mathrm{KRV} \% 2$ 9/Internett\%20\%28KRV\%29/Dokumenter/dokum ent/forvxrevxrapp/Rapport\%209-2009.pdf

White Paper. (2003-2004). Culture for learning (in Norwegian). Oslo: Ministry of Education and Research.

White Paper. (2007-2008). Quality in school (in Norwegian). Oslo: Ministry of Education and Research.

IJEPL is a joint publication of the Association for Supervision and Curriculum Development, the Faculty of Education at Simon Fraser University, and the College of Education and Human Development at George Mason University. By virtue of their appearance in this open access journal, articles are free to use, with proper attribution, in educational and other non-commercial settings 90 days after initial publication. Copyright for articles published in IJEPL is retained by the authors. More information is available on the IJEPL Web site: http://www.ijepl.org 